\title{
The Exploration of Physical Pain, Physical Function, and Vitality of Older People with Diabetes Mellitus in Kalirandu Village
}

\author{
Dinasti Pudang Binoriang*, Lintang Aura Rizki Novitasari \\ School of Nursing, Faculty of Medicine and Health Sciences, Universitas Muhammadiyah Yogyakarta, Yogyakarta, Indonesia
}

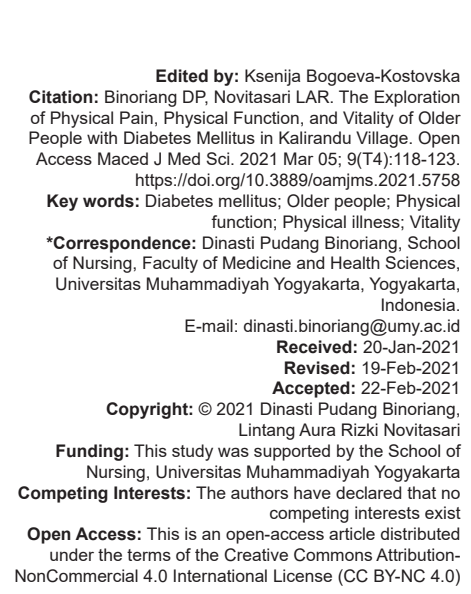

\section{Introduction}

An older people with diabetes mellitus (DM) has many problem related to self-care, adherence to talking medication and also the ability to walk, and some older people feel pain and discomfort due to the symptoms of DM. This will increase to be a serious problem because in general the older people have decreased physiological function, which can lead to poor quality of life in the older people. Aging is a natural process that will occur in every living phase. This process will be experienced starting from birth, growing into adulthood, reproducing, and becoming old. Meanwhile, the elderly is a time phase underwent by people who are blessed with long life [1]. Government Regulation Number 23 the year 2004 about the Implementation of Efforts to Improve Social Welfare for the older people explains that older people are the ones who have reached the age of 60 years old and above.

The elderly is the final phase of life, where the physiological functions of the body will decrease.
This decrease in body function can cause them to be susceptible to degenerative diseases. A degenerative disease frequently found in older people is DM [2].

Based on age, DM in Indonesia was experienced by $6.3 \%$ of people who are $>55$ years old, $6 \%$ of people who are $>65$ years old, and $3.3 \%$ of people who are $>75$ years old. Yogyakarta Special Region (DIY) is in the top three provinces, with the highest incidence of DM in Indonesia [3]. The results of this data collection were supported by data from the Dinas Kesehatan Yogyakarta [4], who showed that DIY has a DM incidence rate of 2891 incidents. These incidents were also found in one of the districts in DIY, namely, Bantul, with a total of 1859 incidents [5]. This disease can become severe and cause complications if it is not appropriately handled. It can cause high morbidity and mortality and decrease the quality of life [6].

The World Health Organization quality of life defines the quality of life as an individual's perception of an individual's position in life concerning the culture and values in which the individual experiences related to goals, expectations, standards, and desires. The 
quality of life in older people is closely related to their awareness of health problems and life habits [7].

Older people without diabetes have a better quality of life than the ones with diabetes [8]. Older people with DM have many problems related to self-care, adherence to taking medication, also the ability to walk, as well as vitality and discomfort due to DM symptoms. Physical function is a description of the physical condition of whether the body is functioning properly and how this physical function affects physical activity in an individual [9]. Meanwhile, physical pain is a description of the disease experienced by individuals currently due to a decrease in physical function and body resistance caused by illness. Physical pain includes how long the pain has been suffered, where the pain is felt and how the description is related to the pain. Quality of life is also related to vitality, which is a person's condition related to energy and enthusiasm in carrying out daily activities and factors that affect the spirit of the individual. In everyday life, vitality can be identified from the enthusiasm of the older people in carrying out activities, rest habits of the older people, and their daily energy and also related to the fatigue frequently experienced by them.

The results of the preliminary study obtained by researchers on October 10, 2019, from the data from the Kasihan 1 Public Health Center, showed that 49 older people living in Bangunjiwo Kasihan Bantul were diagnosed with DM, the 16 of who lived in Padukuhan Kalirandu. Data from Posyandu Werda Pratama also found that there were four older people diagnosed with DM. Researchers are interested in conducting research related to the quality of life of the older people in Padukuhan Kalirandu because, first, there are many cases of older people in the area. Second, research on the quality of life of DM is still very rarely studied, especially in the older people group. Third, there are several studies revealing that the quality of life of older people without DM is better than older people with DM. Therefore, researchers are interested in conducting this research.

\section{Methods}

This study used a qualitative research method with a phenomenological approach. A phenomenological approach is an approach that describes the life experience of an individual with the phenomena experienced. Participants in this study were eight people who were appointed using a purposive sampling technique. The inclusion criteria include the older people who were diagnosed with DM by health personnel, the older people who lived in Kalirandu Padukuhan, and the older people who were willing to become participants and had filled out the informed consent. This research was conducted at Padukuhan Kalirandu, Bangunjiwo, Kasihan Bantul, Yogyakarta, in February-March 2020. The variable in this study was an exploration of the physical pain, physical function, and vitality of older people with DM in Kalirandu Village. The research instruments used in this study were interview guidelines, unstructured observation, and field notes. The data analysis in this study was carried out using the Miles and Huberman method. The method went through the stages of data reduction, data presentation, and conclusions. Ethical clearance was confidentiality, justice, and beneficence with an ethical Health Research Ethics Committee Universitas Aisyiyah Yogyakarta approval number: 1366/KEP-UNISA/I/2020.

\section{Results}

Participants in this study were eight older people from RT 01 - RT 07 Padukuhan Kalirandu. In this study, the results showed that the number of older people participants with diabetes were eight people (100\%), where the most extensive age range of $60-70$ years old was four people $(50 \% \%)$, the majority of primary education levels were six people (75\%), and the majority of DM older people occupation was unemployed with a total of three people (37.5\%).

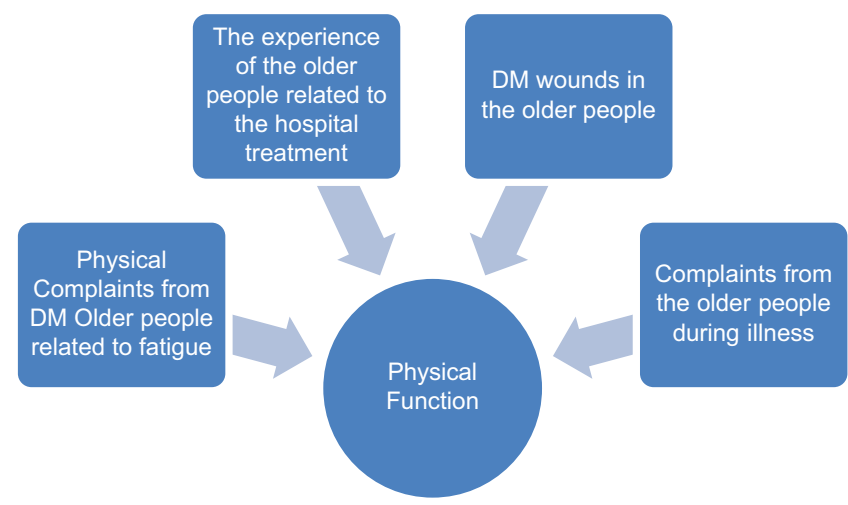

Figure 1: Theme one physical function older people with diabetes mellitus

a. The results of the study that showed the physical function related to older people with DM can be proven by the sub-themes obtained by the researchers as follows (Figure 1):

1. The daily activities of the older people, as evidenced by the following statements: "Starting early in the morning cooking, cleaning like parents usually do, washing clothes, and doing knife crafts and also taking care of grandchildren" (Participant 6)

2. The activities of the older people in the community as evidenced by the following statements: "It is once a month for the recitation, the social gathering is twice a month" (Participant 1)

3. Sports activities for the older people, as evidenced by the following statements: "The exercise is twice a week, every Friday and 
Sunday, a special week for the elderly, while Friday is in the afternoon with RT residents" (Participant 7)

4. Disturbance in activities, as evidenced by the following statements: "Yes, I can't walk, my leg hurts, my thumb is numb, just lying on the bed .. if I'm not mistaken, it has been for 3 months" (Participant 4).

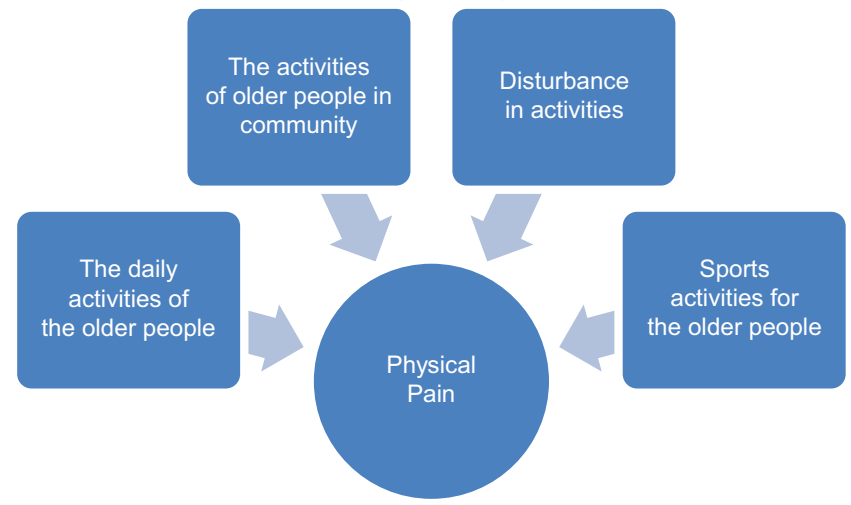

Figure 2: Theme two physical pain older people with diabetes mellitus

b. The results of the study that indicates physical illness in older people with diabetes can be proven by the sub themes obtained by the researchers as follows (Figure 2):

1. Complaints from the older people during illness, as evidenced by the following statements: "My fingers are tingling all the time, you have a headache, I just feel like sleeping, and my body hurts, everything is not good" (Participant 8)

2. DM wounds in the older people, as evidenced by the following statement: "This finger was cut off, the first part of the thumb was missing the nails, and it was watery, then I checked it with Mr. Markus. I've been sick for about 5 years; now I only have half my thumb" (Participant 3)

3. How to treat older people DM wounds, as evidenced by the following statement: "The ointment is soaked by Mr. Markus" (Participant 3)

4. The experience of the older people related to the hospital treatment, which is proven by the following statements: "I was treated at the Gaming Hospital, my blood sugar dropped, it was like a dead person because I couldn't move" (Participant 7)

c. The results of the study that showed the related vitality of older people with DM can be proven by the sub-themes obtained by the researchers as follows (Figure 3):

1. Rest patterns for DM older people, as evidenced by the following statements: "That is, after the midday prayer, until the Asr call to prayer wake up ... at 9 I slept, later at 1 am I would wake up" (Participant 1)

2. DM Older people's Rest Disorders, as

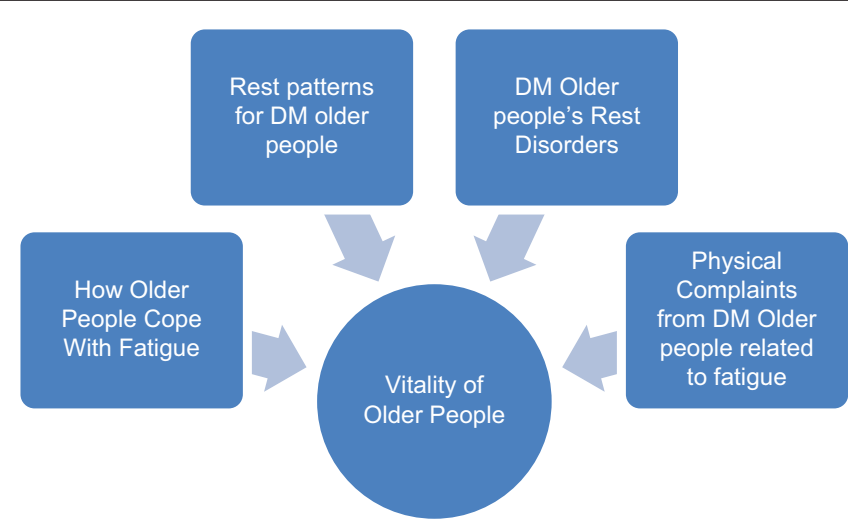

Figure 3: Theme three vitality of older people with diabetes mellitus

evidenced by the following statement: "At most, Grandma wants to have a bathroom" (Participant 6). "Then you have a hard time sleeping, Grandma, you don't know how sleepy her eyes are, but it's hard to brake, sometimes the one that makes you can't sleep" (Participant 8)

3. Physical Complaints from DM Older people related to fatigue, as evidenced by the following statement: "yes I am often tired, weak, always feel sleepy ... if the work is hard, I am tired, I also take care of my grandchildren at home, but yes, because of this illness, I often feel tired"(Participant 8)

4. How Older People Cope With Fatigue, as evidenced by the following statements: "sleep and take medicine" (Participant 4)." massaged using hot oil " (Participant 6)

\section{Discussion}

\section{A. Physical Function of DM Older People}

The results of this study indicate that older people with DM still perform daily physical activities. They are classified as light physical activities such as cooking, cleaning, and washing clothes, doing work according to their profession, such as massaging babies, trading, and making crafts. Some older people also still actively participate in community activities such as recitation, social gathering, and mutual assistance. However, there are some older people who have not participated in activities in the community due to feelings of fear about fatigue after participating in the activities. Physical activity is the movement of the limbs produced by skeletal muscles. Everyone has variations in carrying out physical activities such as working, eating, resting, or recreating. This research is in line with the study conducted [10], revealing that the older people with $\mathrm{DM}$, in general, can still do physical activity in the light category (96\%) and the moderate category (4\%). 
The results of this study also stated that some older people actively participate in Posyandu activities in the Padukuhan, one of which is gymnastics. Exercises carried out are special exercises for older people, and there are also special leg exercises for older people with DM, which are done approximately 30-60 min once a week. Some other older people do sports by strolling in the morning for 15-30 min every day. However, there are also older people who have not done exercises at all because of the complaints they experience. The older people said they felt tired more often due to physical activity. The older people also stated that they were disturbed and could not do a physical activity because of the pain they experienced, such as a leg wound and a high blood sugar level. This research is also supported by research conducted [11], explaining that the majority of DM older people perform physical activities in the active category (54.2\%) such as low-intensity sports once a week with a duration of $30 \mathrm{~min}$, social or religious activities, grandchildren caring activities, and also household chores.

The pattern of physical activity is closely related to blood glucose levels in older people with DM. The physical activity carried out by a person can increase the sensitivity of insulin receptors so that glucose can be converted into energy through metabolism [12]. One of the benefits of physical activity is that it can reduce blood sugar levels in people with diabetes, prevent obesity, play a role in preventing complications, and increase blood pressure. When physical activity is carried out, the muscles in the body will react using the stored glucose; thus, the stored glucose is reduced. In this situation, there will be a muscle reaction in which it will take up glucose in the blood so that the glucose decreases and improve blood glucose control. Individuals who are active in physical activity have better insulin and glucose levels than inactive individuals. Physical activity mechanisms play a role in preventing or inhibiting the development of DM [13].

Apart from playing a role in lowering blood glucose levels in DM sufferers, preventing obesity, playing a role in preventing complications, and physical activity also plays an essential role in improving the quality of life for older people with DM. Older people with DM and high physical activity had a good quality of life $(97.6 \%)$ and adequate quality of life $(2.4 \%)$ than those who did moderate and low physical activity [14].

\section{B. Physical IIIness of Older People with DM}

The results of this study indicated that some older people with DM had been hospitalized. This condition is caused by the physical condition of the older people who are weakened due to high blood glucose levels so that they need immediate treatment in the hospital. The older people stated that when they were treated in the hospital, they were given rapid treatment, namely, in the form of pharmacological action with drugs and insulin to the lower their blood sugar levels.
DM is a disease that does not persist continuously. Older people with DM will feel inevitable complaints or signs of symptoms when their blood glucose levels are high or even when it is a low level. However, under normal conditions, older people will not feel these signs. Those with DM will experience tingling symptoms, weakness in the body, frequent hunger, and also frequent urination at night [15].

Furthermore, the results of this study indicated that most older people with DM experienced physical complaints during the period of DM, such as body weaknesses so that it does not have the strength to do activities, frequent tingling feeling in the extremities, frequent headaches with a spinning or choking sensation, pain in the legs and radiating to the back, and also frequent drowsy feeling.

DM is also a disease that cannot be cured but can be controlled to prevent complications. Complications in DM sufferers are the result of uncontrolled blood glucose levels. They are also determined by the length of time suffering from DM disease. The complications are divided into two, namely, acute complications and chronic complications [12]. Diabetic ulcers are a chronic complication due to uncontrolled blood sugar levels that cause damage to small or microvascular blood vessels in the extremities, especially the lower extremities, namely, the legs.

The results of this study found that two older people had complications of diabetic ulcers or diabetic wounds on the feet and had suffered from diabetes for more than 5 years. Meanwhile, older people with DM for $<5$ years did not find complications of diabetic ulcers. It is in line with the research conducted [16] revealing that gangrene or diabetic ulcer is the most common complication in DM sufferers, especially in older people, with a total of 39 people $(20.2 \%)$.

The results of this study also showed that the treatment of ulcer wounds in the clinic was carried out by washing it with water and then scissors on the dead tissue, while the homecare was carried out independently by the older people themselves by rinsing with clean water then applying ointment to the wound area. Most of the participants treated ulcer wounds independently by washing and cleaning them with $\mathrm{NaCl}$, while treatment for ulcers with holes and dead tissue was carried out by health professionals [17].

\section{The Vitality of the Older People with DM}

The results in this study indicated that older people with diabetes have a pattern of resting twice a day, namely, day and night. The majority of the older people took $3 \mathrm{~h}$ of naps from day to evening while, at night, they slept $8 \mathrm{~h}$ from $9 \mathrm{pm}$ to $4 \mathrm{pm}$ or dawn. They explained that they often wake up at night to urinate. Several other older people also said that they frequently experience the insomniac disorder. 
Sleeping is essential for older people to keep control of their blood glucose levels in addition to pharmacology, diet, and physical activity. Someone with DM has a long sleep time. When they are likely to have a short sleeping period, it is because someone with DM will experience polyuria and nocturia at night, which requires waking up so that it can disturb their sleep. Disrupted sleep can trigger an increase in sympathetic nerve activity and trigger an increase in the cardar hormone cortisol, where it can be in the form of glucose so that DM patients can increase their blood pressure. Hyperglycemia at night can be aggravated by decreased insulin production at night. Thus, DM patients with poor sleep quality can cause instability in blood glucose levels [18].

In another research, it is also stated that 43 DM patients (63.2\%) had poor sleep quality [19]. This poor quality of sleep was caused because the patient had polyuria so that they had to wake up at night. This research is also supported by research conducted [20], which revealed that poor sleep quality is, on average, $64.4 \%$ of people over 60 years old. In the study, it was also stated that poor sleep quality tended to occur to someone who was over 60 years old and had a high blood sugar level of $59.6 \%$.

Furthermore, the results of this study also explained that older people were likely to feel exhausted. They stated that they felt tired more often, even though they were not doing strenuous activities. They, moreover, also mentioned that they had physical complaints when experiencing fatigue, including pain in the extremities and back pain. However, the older people could overcome the fatigue they experienced in several ways, including resting sleep, massaging the affected area, and applying a little oil or balm to the areas that experience pain when they were in fatigue condition.

In another research, it is explained that there was no specific relationship between fatigue in DM sufferers and physical activity [21]. Fatigue is a symptom that frequently appears in DM sufferers, especially the older people, when their blood sugar is high. However, a history of DM is not the main factor causing fatigue. Older people with DM are highly suggested to take a rest, having enough energy to restore their health condition to get back to their prime. This research is supported by another research conducted [22], which states that physical fatigue in older people with DM also had a close relationship with the quality of their sleep. The results showed that 15 older people with good sleep quality had mild fatigue, while 75 older people with poor sleep quality experienced severe fatigue.

\section{Conclusion}

Based on the data explained, it can be concluded by identifying the sub-themes obtained by the researchers, related to how the older people do daily activities, activities in the community, sports activities, and disorders of the older people in carrying out their activities. Physical illness related to the quality of life of the older people with DM can be seen from the sub-themes obtained by the researchers, namely, several complaints of the older people during illness, $\mathrm{DM}$ in the older people, how the older people treat DM wounds, and the experience of the older people related to hospital treatment. Vitality, related to the quality of life of the older people with DM, can be seen from the subthemes obtained by the researchers, which explained older people's rest patterns, rest disorders, physical complaints related to fatigue, and also how they deal with physical complaints related to the fatigue. In terms of further research, the researchers are suggested to conduct quantitative research to scrutinize the factors that affect the quality of life of older people and also identify the prevention of a decrease in quality of life in older people with DM.

\section{References}

1. Fitrie U, Djalali DM. Self-acceptance, social support and happiness in the older people. Persona 2016;5.

2. Saiful G, Septiawan $C$. The effect of four variables on the quality of life of the older people with Type I diabetes mellitus. Indones Sci J Nurs. 2018;8:450-61.

3. RISKESDAS. Hasil Utama Riset Kesehatan Dasar. Jakarta: Kemenkes RI; 2018.

4. Dinas Kesehatan Yogyakarta. Profil Kesehatan Tahun 2015 Kota Yogyakarta. Yogyakarta: Dinkes; 2015.

5. Dinas Kesehatan Kabupaten Bantul. Profil Kesehatan Kabupaten Bantul. Bantul: Dinkes; 2017. https://doi.org/10.33560/jmiki. v7i2.240

6. Margaretha T. Quality of life Type 2 diabetes mellitus at public health center Kupang city. J Health Info. 2017;1:119-34.

7. Astika SR, Yulianti A. Mindfullness with quality of life in the older people. J Psychol 2017;13:48-54.

8. Wändell PE. Quality of life of patients with diabetes mellitus an overview of research in primary health care in the Nordic countries. Scand J Prim Health Care. 2005;23(2):68-74. http:// doi.org/10.1080/02813430510015296.

PMid:16036544

9. Mark K, Keller SD, Ware DJ. A 12-item short-form health survey: Construction of scales and preliminary tests of reliability and validity. Med Care. 2019;34(3):15. https://doi. org/10.1097/00005650-199603000-00003

10. Gita LA, Hidajah AC. The relationship between education, sports habits, and diet and quality of life of the older people at wonokromo health center, Surabaya. Health Promot J. 2017;4(1):59

11. Ahmad F. The Relationship between Physical Activity and Sleep Quality in the Older People. Faculty of Health Sciences. Surakarta: University of Muhammadiyah Surakarta 2016;13.

12. Perkeni. Konsensus Pengelolaan Dan Pencegahan Diabetes Melitus Tipe 2 Di Indonesia. Perkeni; 2015.

13. Nurayati L, Adriani M. Association between Physical Activity and Fasting Blood Glucose among Type 2 Diabetes Mellitus 
Patients. Departemen Gizi Kesehatan, Fakultas Kesehatan Masyarakat-Universitas Airlangga; 2017.

14. Timisela JC, Ratag BT, Kalesaran AF. Hubungan Aktivitas Fisik Dengan Kualitas Hidup Pasien Dm Tipe li Di Rsu Pancaran Kasih; 2017.

15. Dwi MF, Suwandi JF, Karyus A. Pharmacological management of Type 2 diabetes mellitus in older people women with uncontrolled sugar levels. 2016;5:7.

16. KhmA, Fitriani N. Characteristics of complicated diabetes mellitus inpatients in the internal medicine section of Rs Muhammadiyah Palembang for the period of January 2013-December 2013. Syifa Medika: J Med Health. 2015;6(1):53. https://doi. org/10.32502/sm.v6i1.1380

17. Hasan BM. The experience of Type $2 \mathrm{dm}$ patients in doing diabetic ulcer care independently. Endurance J. 2019;4(1):58.
18. Siti R, Septiawan CD. Sleep Quality with Blood Glucose Levels in Type 2 Diabetes Mellitus Patients at X Hospital Palembang; 2016. p. 10.

19. Mulyadi KJ, Rottie JV. The Relationship between Sleep Quality and Fasting Blood Glucose Levels in Type 2 Diabetes Mellitus Patients at Pancaran Kasih Gmim Manado Hospital; 2017. p. 10.

20. Tri S, Lintang D, Sawaraswati D, Muniroh M. Description of sleep quality in patients with Type 2 diabetes mellitus in the work area of the Ngesrep community health center. J Public Health. 2018;6:13

21. Sunarto R, Maftuhah N. Factors related to fatigue in the older people in Umbulmartani Village, Sleman, 2015. Indones J Med Health. 2015;6(4):188-97.

22. Nurfa Al. The Relationship between Sleep Quality and Physical Fatigue in the older People. Department of Nursing, Faculty of Medicine. Diponegoro: Diponegoro University; 2017. 